\title{
How and Why Do Social and Sustainable Initiatives Scale? A Systematic Review of the Literature on Social Entrepreneurship and Grassroots Innovation
}

\author{
Marion van Lunenburg $^{1} \cdot$ Karin Geuijen $^{1} \cdot$ Albert $^{\text {Meijer }^{1}}{ }_{(D)}$
}

Published online: 3 March 2020

(C) The Author(s) 2020

\begin{abstract}
Social and sustainable initiatives generally start small and need to scale to create substantial impact. Our systematic review of 133 articles develops a better understanding of this scaling process. From the literature, we conceptualize impact as the result of two different pathways: 'scaling out' (extending geographical space or volume) and 'scaling up' (influence on public discourses, political agendas and legislation). The review identified strategy, actor characteristics and institutional environment as key factors for scaling. The literature indicates that for strategy a focus on open structures generates speed and higher impact, but we also found critical views on this. The literature shows that the actor characteristics such as the ambition to scale, equal focus on the economic and the social logic, entrepreneurial skills and leadership are positively related to the level of impact. The institutional environment influences actor characteristics and strategy choices and also has a direct effect on the level of social and sustainable impact.
\end{abstract}

Keywords Scaling - Social and sustainable initiatives . Social impact · Social entrepreneurship · Grassroots innovation

Albert Meijer

a.j.meijer@uu.nl

1 Utrecht School of Governance, Bijlhouwerstraat 6, 3511 ZC Utrecht, The Netherlands

\section{Introduction}

Social and sustainable initiatives generally start small, but some of them manage to create an enormous impact when they scale. Research has shown that local initiatives can form the starting point for processes of transformation by bringing in new ideas and generating public support (Doberstein 2016; Bason 2010; Fung 2015; Geuijen 2014; Cloutier et al. 2015). These initiatives may also have an impact on policies and even transform national and international systems (Seyfang and Smith 2007). At the moment, however, our academic knowledge of scaling these initiatives is limited.

There are well-known examples of successful scaling such as the Alzheimer Café and the Instock Restaurant. At the Alzheimer Café, families meet peers, professionals and students in an informal setting. It started in The Dutch city of Leiden in 1997, and at the moment there are 230 Alzheimer Cafés in the Netherlands. The idea has been picked up in other countries as well. The Instock restaurant prepares high-quality meals from wasted ingredients. In 2015, four ambitious employees of a big supermarket in the Netherlands started it, and meanwhile, they have not only increased the number of restaurants, but also put food waste on the political and public agenda. These examples are highly interesting, but an academic understanding of these successful forms of scaling is lacking.

Scaling local initiatives turns out to be rather difficult (Hermans et al. 2016). How, why and under what conditions initiatives scale are important questions, but academic knowledge is limited and fragmented. In addition, this subject is researched in different academic domains with their own terms and jargon. A systematic review on the literature of the scaling process of social and sustainable 
initiatives is needed to develop a better and more precise understanding of this process in different areas.

Systematic reviews are based on systematic methods (Tranfiels et al. 2003) and aim to gather, evaluate and synthesize all studies on a topic (Popay 2005). They also identify the gaps in the literature to help further scientific knowledge (Kitchenham 2004). Despite their complex and time-consuming nature (Mills et al. (2005), systematic reviews are of key importance since they contribute to the academic literature and also be a methodological advance for the field.

The present literature review aims to answer the research question: How and why do social and sustainable initiatives scale? This paper aims to build a framework that synthesizes the state-of-the-art of the fragmented literature in an accessible manner. It provides the basis for research into the scaling mechanisms of initiatives that start bottomup by presenting the state-of-the-art knowledge on this topic (what do we know and where are the gaps) and by providing the conceptual understanding that is needed to study this topic.

\section{Central Concepts, Search Terms and Definitions}

\section{Central Concepts}

A literature review of scaling processes of local initiatives is complicated in view of the variety of terms and concepts that are being used to refer to the same or similar processes, in different areas. To get more focus, we distinguished four central concepts-(1) actor characteristics, (2) strategic choices, (3) institutional factors and (4) impact-based on the literature on strategic management (Trau 2017; Eshima and Anderson 2017; Kraus and Rigtering 2017) and environmental issues (Hossain 2016; Martiskainen 2017; Seyfang and Longhurst 2013a). The four concepts refer to choices to be made by actors or organizations acting in a certain context, with the aim to increase their impact.

\section{Search Terms}

The systematic review was an iterative process that we used to specify the central concepts in more detail. At the start of our research, we thoroughly considered what search terms cover our main interest the best. Selecting search terms turned out to be more complicated in view of the variety of terms that are being used to express 'local initiatives'. An initial exploration of these terms helped to select our search terms for the literature review.

The term 'bottom-up initiatives' is often used as an umbrella term to express initiatives that start locally. This umbrella term, however, is not used as much as the underlying, more specific terms. A systematic review of grassroots innovation literature showed that almost all articles were published in journals that focus on the environmental research areas (Hossain 2016). Grassroots innovation would therefore only cover the sustainable initiatives in our review and provide limited information about scaling of social initiatives.

We considered 'social enterprise' as search term. However, following the definition of social enterprise in Roy et al. (2014) as 'business with social objectives whose surplus revenue is reinvested for these purposes', we would have excluded other forms of social entrepreneurial behaviour, for example by employees or individual citizens. We follow Becker et al. (2017) who have combined the literature on community energy (grassroots innovation) with that of social entrepreneurship and found this fertile ground for mutual advancement. By including the concept social entrepreneurship, we not only covered the social initiatives, but also enriched the literature on grassroots innovation. In order to check whether we did not omit relevant literature on specific geographical areas or research domains by selecting 'social entrepreneurship' as our search term, we compared this term with 'social enterprise'. In the period which our research covers, we did not find a difference between these two terms, neither geographically nor in research area.

In brief, besides 'bottom-up', we include two search terms that represent social and environmental initiatives more specifically: grassroots innovation and social entrepreneurship. We searched on these terms AND 'scaling'.

\section{Definitions}

Grassroots innovation is seen as a bottom-up process that focuses on the creation of public value. Seyfang and Smiths' (2007) definition of grassroots innovation is widely used in the literature:

(...) networks of activists and organizations generating novel, bottom-up solutions for sustainable development, solutions that respond to the local situation and the interests and values of the communities involved. (Seyfang and Smith 2007, p. 585).

Although a clear definition of social entrepreneurship is still missing, they share the dual focus on economic goals and their social challenges (Becker et al. 2017; Zahra et al. 2009; Santos 2012; Smith and Stevens 2010). Some authors also refer to environmental challenges (Becker et al. 2017).

Scaling is defined as 'increasing the impact a social (or sustainable)-purpose organization produces' (Dees 2008, p. 18 in Smith et al. 2016). However, the literature provides many different perspectives on scaling, and it is not clear 
how social and sustainable impact can be understood. For this reason, we decided to use the literature to develop a conceptual understanding of scaling and impact that could form the basis for further research.

\section{Methodology}

\section{Search Strategies for Identification and Selection of Studies}

We adopted the systematic literature review (SLR) as our method. SLR was grounded in Medical Science (Cook et al. 1997) and adopted in the field of management and entrepreneurship (Tranfield et al. 2003) and in environmental studies (Hossain 2016). This method was used to provide a framework for identifying the gaps in the literature relevant to scaling social and sustainable initiatives and for synthesizing the existing findings. Systematic reviews improve the quality of the review process and outcome by employing a transparent, reproducible procedure (Tranfield et al. 2003). Following SLR guidelines, the review process consists of three stages: data collection, assessment and clustering for analysis and reporting.

\section{Data Collection}

On 5 May 2017, we identified 1.838 studies by searching the Web of Science (SSCI, SCI en A\&HCI) database on the topics 'bottom-up initiatives' (494), 'grassroots innovation' (172) and 'social entrepreneurship' (1.172). Only articles were included. Articles not written in English were excluded. To keep our focus on the scaling process and reduce the number of articles, we infused our search with 'scaling'. This resulted in 271 articles (bottom-up 76; grassroots innovation 26; social entrepreneurship 169).

\section{Inclusion Criteria for Studies to Review}

After duplicated were removed, 269 abstracts and (sometimes) content were screened on two inclusion criteria: (1) studies that regarded the broader public domain and (2) studies concerning scaling in the context of growth, distribution or transformation. This resulted in 133 articles (bottom-up 55; grassroots innovation 22; social entrepreneurship 56) (Fig. 1).

\section{Assessment Process and Coding}

The assessment was done by the first author, a PhD student. Every step was taken in close consultation with the supervisors of the team, being the second and third author. We started our analysis with a rough division of variables taken from the central concepts: 'strategic scaling choices', 'actor characteristics', 'institutional factors' and 'impact'. We also looked at the year of publication, the research area, whether a study was evidence based or not and the perspective. In order to cluster our data, we had to develop a more detailed code scheme, so we read and re-read the articles in an iterative process. In this way, we doublechecked whether all articles matched the criteria. Every step in this process was discussed in the team.

\section{Overall Findings}

Our analysis of the selected set of publications showed that the first publications on bottom-up initiatives and scaling date from 1997, those on social entrepreneurship from 2003. Based on a systematic review of grassroots innovation done by Hossain (2016), we expected a dominant focus of the environmental areas in grassroots literature, but we were surprised that the environmental areas also dominate the literature on bottom-up initiatives. Although environmental areas were found in $28 \%$ of the literature on social entrepreneurship as well, business and economics was dominant $(67 \%)$.

Table 1 shows that $60 \%$ of the articles was based on empirical research. In 20 studies, quantitative methods were used. Although the quantitative data did not refer to the variables in the scaling process in which we were interested, it did bring us useful information on the how and why in the scaling process.

Most empirical studies were based on qualitative research methods (62). Fifty-two out of 62 qualitative studies were case studies. Forty percentage of the studies was based on secondary data, but these data may also represent empirical evidence. Sometimes experts were interviewed about their opinions on how to encourage local initiatives. We classified these interviews as secondary data, but the empirical classification would be defendable as well. All in all, most studies were based on empirical data.

The dominant theme in the literature on bottom-up initiatives was 'how to involve the public'. Most studies were done from the perspective of the institutional environment $(65 \%)$. The literature on social entrepreneurship frequently discussed the characteristics and position of the social entrepreneur compared with the traditional entrepreneur. As a result, more studies on social entrepreneurship were done from the perspective of the entrepreneur (49\%). 
Fig. 1 Flow diagram of the literature screening process

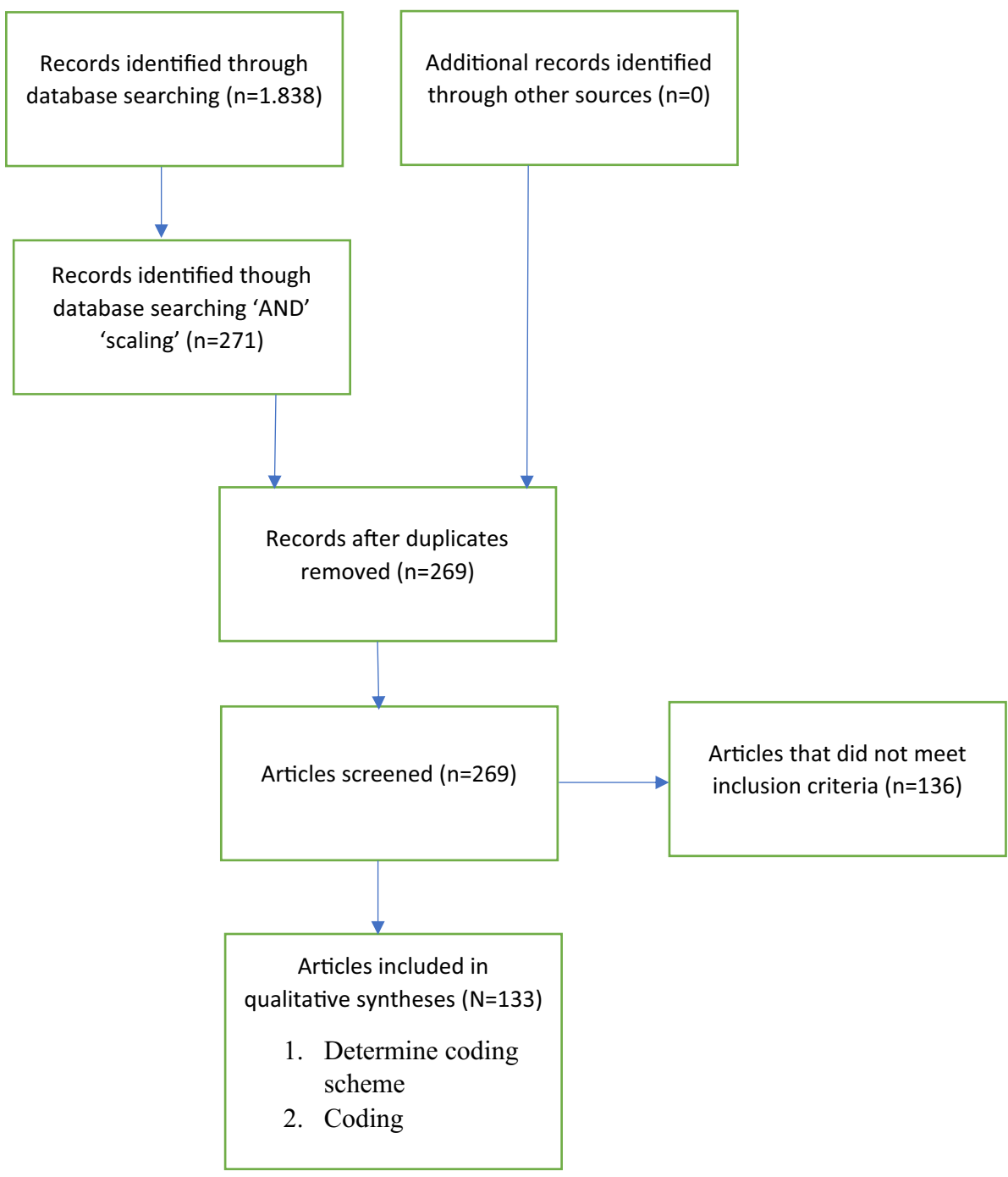

Table 1 Type of research

\begin{tabular}{lll}
\hline Empirical & Not empirical & Total \\
\hline $80(60 \%)$ & $53(40 \%)$ & $133(100 \%)$ \\
60 qualitative & 44 literature, review & \\
20 quantitative & 7 (database) analyses & \\
& 2 expert interviews ${ }^{\mathrm{a}}$ & \\
\hline
\end{tabular}

${ }^{a}$ Experts were interviewed for their opinions and normative visions. We therefore classified this study as not empirical

\section{Impact: Volume, Geographical Distribution and System Change}

Scaling is not an objective in itself but is seen as a strategy to realize more impact. All 133 articles are on scaling purposes that improve social, welfare, health or physical environmental issues. Impact as success indicator was mentioned in 20 studies. In 17 studies (15 more general studies on bottom-up initiatives and 2 specifically on grassroots initiatives), the impact was considered as some form of prevention (14) or compliance (3) in the environmental of healthcare context (for example, protected cost management, smoking). In the remaining 19 articles (of 56), impact was implicitly defined in terms of 'better education', 'access to energy', 'empowerment of women' and so on, mostly in the context of individual cases.

The types of impact are very diverse and highlight depending on the specific issue at hand. They may also be focused on narrow or broader issues. In more general terms, our analysis highlights that impact refers to social and sustainable impact which can be expressed in (1) volume, (2) geographical distribution and (3) system change. The three dimensions can be used to assess whether scaling has resulted in impact. 


\section{Strategy Choices: Pathway and Structure}

In the diverse set of academic publications, we found two main strategy choices for scaling which we label as 'pathway' and 'structure'.

\section{Pathway: 'Scaling Up' or 'Scaling Out'}

The different perspectives in scaling processes were recognized by Westley et al. (2014) and Hermans et al. (2016). They labelled all organization's efforts to affect more people and cover a larger geographic area as 'scaling out' and reserved the term 'scaling up' for identifying opportunities and barriers within institutional structures to properly embed an innovation and the actions that niche actors employ to achieve that. Among these are creating and fine-tuning technologies, linkage building through intermediation activities, advocacy and lobbying, mobilizing powerful 'patrons', and creating alternative visions, framings and discourses. Vertical or political scaling was mentioned as an equivalent of 'scaling up' (Kempers et al. 2015; Radywyl and Biggs 2013; Andre and Pache 2016). The literature highlights that the results (impact) of scaling up and scaling out are measured on different levels (Westley et al. 2014). Scaling out focuses on increasing numbers, from local to international or from small to big networks. Scaling up focuses on influence on local to international political agendas, public discourses or legislation.

These two perspectives on scaling-scaling up and scaling out - show that we need to study local initiatives' scaling as two separate but possibly also interrelated processes of making more impact: either by reaching more people and a larger geographical area or by changing institutional structures. The literature suggests that local initiatives may choose one or both forms to strengthen their impact. We explored the strategic choices of local initiatives to enhance our understanding of these two possible routes to more impact.

Pathway is not explicitly discussed in many articles. As initiatives can simultaneously scale up and out, a certain article could cover both. So, 54\% covered scaling up and $60 \%$ scaling out. The bottom-up literature mainly refers to scaling up in the sense of influencing policy making $(64 \%$ of 55 articles). Key strategic issues are creating awareness, positive entrepreneurial environment, institutional context and inclusive policy making. In this context, Westley et al. (2014) and Quinn et al. (2014) introduced institutional entrepreneurship as a concept and condition for scaling up successfully. The literature on social entrepreneurship relatively covered scaling out the most (64\% of 56 articles). We found replication, distribution of services, (financial) growth, differentiation, diversification and market development as strategic issues in scaling out. Replication was a dominant way to scale out in bottom-up and grassroots literature.

Little is known about the effects of pathway choices on social and sustainable impact. One study on the scaling process of grassroots innovations in the agricultural area showed that although they had the same challenges, grassroots initiatives all had their own pathways that strongly differ from each other, and it is impossible to draw any conclusions on successful strategies (Hermans et al. 2016).

\section{Structure: Open or Closed}

One important reason for the variance in scaling outcomes is the use of different structures, or organizational modes, of scaling). Structure is defined as the way in which initiatives organize their activities: choosing a more open or a more closed structure. This strategy choice is linked to the concept of organizational scaling (Bocken et al. 2016) and was implicitly covered by $75 \%$ of the articles. Structure is mostly discussed in the literature on social entrepreneurship. Warnecke and Houndonougbo (2016) distinguished four ways for organizational scaling: expanding the organization, establish strategic networks, affiliation/branching or informal/loose networks just to spread an idea. Smith and Stevens (2010) suggested three structure strategies for scaling: dissemination, affiliation and branching. Dissemination would be the most open structure; branching expresses the most control. Franchising sits between branching and affiliation. In the more general literature on bottom-up initiatives as well as in the more specific literature on grassroots initiatives, the collaborative structure dominated. It was also seen as the most successful strategy for scaling environmental issues (Hermans et al. 2016; Becker et al. 2017; Elbakitze et al. 2010; Andrews et al. 2012; Vergragt and Brown 2012; Hatzl et al. 2016). However, we also found studies that took a critical view on the success of a collaborative strategy. These argue that collaboration could frustrate the scaling process due to internal conflicts and slow learning (Vergragt and Brown 2012; Mair et al. 2016).

The literature on social entrepreneurship was sometimes fully devoted to the relation between strategic choices on structure and impact. In general, social enterprises opt for organizational structures that resemble franchise or network models, implying that multiple bodies coexist, all with some degree of autonomy (Voltan and Fuentes 2016). We found evidence that open structures like franchising generate more impact in comparison with formal structures (Auvignet and Lloret 2015; Smith and Stevens 2010; Beckmann and Zeyen 2014; Krzeminska and Zeyen 2017). 
Open structures also speed up the scaling process (Smith et al. 2016). The relationship between structure and impact is not clear. While some studies find that an open structure implies more and faster impact, other studies contradict this. It seems that actor characteristics interfere. An entrepreneur who desires control would choose a less open structure more often (Smith et al. 2016). This would imply that preferring control would lead to a slower pace of creating impact. However, studies also show that commercial entrepreneurs-who generally desire for controlscale out faster as they are professionally organized and have better access to resources (Hatzl et al. 2016). So, the relation between structure and impact seems to be mediated by actor characteristics. We will discuss this more in depth in the next section.

In sum, strategic choices consist of the choice for a pathway and the choice for a structure. The literature provides a fragmented and inconclusive overview of the relation between pathway and social and sustainable impact. An open structure seems to speed up scaling the most, but this might also depend on actor characteristics. For this reason, we explored the literature further to understand how strategic choices and impact are influenced by actor characteristics.

\section{Actor Characteristics: Willingness and Ability to Scale}

The characteristics of actors can be organized in many ways. Scheuerle and Schmitz (2016) introduced two specific actor characteristics as conditions for scaling: willingness and ability. ${ }^{1}$ We will apply these concepts below when reporting our findings on actor characteristics.

\section{Willingness to Scale}

The first actor characteristic we will discuss is the actor's willingness to scale. The literature distinguishes three subcategories of the actor's willingness to scale an initiative: first his or her ambition to scale, second their desire to control, and third which logic would be dominant. Fiftytwo percent of the articles covered one or more aspects of this concept willingness.

\section{Scale Ambition}

Ambition to scale was covered by $44 \%$ of the articles. They indicate that scale ambition differs among initiatives (Becker et al. 2017; Scheuerle and Schmitz 2016; Smith

\footnotetext{
1 The third condition that was mentioned was 'admission'. This concept refers to the institutional environment.
}

et al. 2016; Westley et al. 2014; Hufen and Koppenjan 2015; De Bruin 2016; Gutberlet et al. 2016). Different types of social entrepreneurs would have different scale ambitions. Zahra et al. (2009) distinguish three types of social entrepreneurs. The social bricoleur focuses on the local needs and will hardly touch the existing institutional context. The social constructionist aims to replicate an innovation to different geographical areas, and the social engineer wants to break the (international) social system radically and focuses on the political agenda.

The literature indicates that scale ambition is related to the level of impact. A focus on local needs was seen as a barrier for scaling (Hatzl et al. 2016; Kirwan et al. 2013; Nel et al. 1997; Seyfang and Longhurst 2013b; Bailey et al. 2010; Smith et al. 2014; Gasperi et al. 2016). Whereas social bricoleurs do not want to scale in the first place, the constructionist will scale up and/or out to the regional and national level and the engineer even to the global system. So, scale ambition is related to impact, but literature does not allow to draw conclusions on a relation between scale ambition and pathway or structure choices.

\section{Desire for Control}

The second subdivision of the concept concerning the actor's 'willingness to scale' is the actor's 'desire for control'. Smith et al. (2016) found that a scaling process will be delayed if the social entrepreneur has great ambitions, but also feels a strong desire for control. This result was explained by the actor's preference for an open or formal structure. Smith et al. (2016) presumed a relationship between the actor's wish to control, his or her strategic choice for a certain type of structure and the impact created by the initiative. A formal structure would be chosen by entrepreneurs who want to control, while open structures speed up scaling more than formal structures. Smith and Stevens (2010) explored this further by correlating structure choice and the threefold categories of Zahra et al. (2009). They assumed that the strength of the ties in the network is related to the desire for control: the stronger the network is, the less the actor desires for control. As a result, the local bricoleur will opt for an open structure, whereas the social engineer will opt for branching. Building upon Smith et al.'s (2016) reasoning, it would paradoxically be expected that the social engineer would be less successful in scaling due to their choice for a less open structure. As we have indicated above, Hatzl et al. (2016) found the same paradox for commercial entrepreneurs. So, the desire for control turns out to be directly related to the choice for a certain structure. It is indirectly related to the impact created. 


\section{Logic: Economic and Social}

The third subcategory, which is implicated in the actor's willingness to scale, is whether the economic logic or the social logic prevails in his or her plans and actions. Logic was covered by $20 \%$ of all articles, of which $75 \%$ was literature on social entrepreneurship. Initiators who could simultaneously act in accordance with both economic and social logics turned out to be more successful in scaling (Morris et al. 2011; Fosfuri et al. 2016). They can sustain in their social focus, whereas social entrepreneurs, who do not focus on economic goals at all, would lose their social focus over time due to external pressure (Andre and Pache 2016). As a result, (social) impact decreases.

It turns out that the prevalence of either the economic or the social logic is related to the impact which is created. However, no final conclusions on the relation between logic and pathway and structure can be drawn from the literature.

In sum, we found that scale ambition, desire for control and logic are related to impact. We do not know whether these characteristics are related to pathway: strategic choices for scaling out and/or scaling up. Desire for control seems to be related to structure choice. These findings, however, are mostly based on the literature on social entrepreneurship. We found less studies on the actor's willingness to scale in grassroots innovation or bottom-up initiatives. We know grassroots innovation focuses on the local community, so we might consider grassroots innovators as social bricoleurs who have low ambition to scale and might have strong tights and therefore choice for an open structure. This might also explain the dominant position of collaborative structures, but we cannot draw hard conclusions on that.

\section{Ability to Scale}

Above we indicated that the actor's characteristics consist of two relevant aspects. We have discussed 'willingness' to scale above. The second factor in actor characteristics we discuss is 'ability'. This aspect was covered by $47 \%$ of the articles. Ability to scale represents the way in which initiatives can act upon the institutional context. We distinguished three subcategories of the actor's ability to scale, being first entrepreneurial skills, ${ }^{2}$ second leadership, and third dependency on money, knowledge and network (resources).

\footnotetext{
${ }^{2}$ For legibility reasons, we clustered political, social, economic and marketing skills.
}

Entrepreneurial Skills

Entrepreneurial skills are crucial for scaling. These are needed to get political or financial support (Westley et al. 2014; Calvo-Urgarteburu et al. 2017; Kempers et al. 2015; Warnecke and Houndonougbo 2016; Radywyl and Biggs 2013; Loosemore 2015), to build networks, to hire professional staff, to communicate with stakeholders (Smith and McBride 2015; Sofo 2008; Hatzl et al. 2016; Osterblom et al. 2010; Spiegel et al. 2011), to work efficiently, to build a proper business case and to develop marketing strategies (Zahra et al. 2008; Vergragt and Brown 2012; Brocken 2015; Reeves et al. 2014; Pless and Appel 2012; Perrini et al. 2010; Fosfuri et al. 2016). In the literature, most case studies were presented as successful, meant to learn from. In this context, actors having enough entrepreneurial skills were crucial for success. We therefore may conclude that the more entrepreneurial skills actors have, the more likely the initiative creates impact (on the condition that the actor's willingness to scale is high). However, we did not find information on how entrepreneurial skills and the two strategic choices, pathway and structure, are related.

\section{Leadership}

Next to having entrepreneurial skills, leadership is the second subcategory of the actor's ability to scale. Leadership refers to both managing the internal organization and (proactively) dealing with the external circumstances (Nel et al. 1997; Osterblom et al. 2010; Sofo 2008; Biggs et al. 2010; Warnecke and Houndonougbo 2016). We classified leadership apart from entrepreneurial skills as an actor who has high leadership skills and low entrepreneurial skills could still create high impact. This leader might proactively search for the help of others, for example by collaboration in a network or by participating in a franchise structure.

\section{Dependency on Resources}

The third and final subcategory indicating the actor's ability to scale is dependency on money, knowledge or network. This concept was often mentioned when discussing collaboration of grassroots and bottom-up initiatives, especially in environmental issues like coast protection. These issues either require high levels of knowledge and investments or they can only be solved by including a great diversity in stakeholders. In this way, a high dependency on resources requires high entrepreneurial skills and/or it would more often lead to the choice for open structures. Dependency on resources obviously is relevant for structure choice. 
To conclude, the literature shows that actor characteristics influence the scaling process towards impact. In the previous section, we discussed the actor's willingness to scale, and in this section, we discussed the actor's ability to scale. Two subcategories of the actor's ability are positively and directly related to impact, being entrepreneurial skills and leadership. However, dependency on resources seems to be only indirectly related to impact, being through structure choice. We did not find evidence for a relation between ability and pathway.

\section{Institutional Factors: Rules and Support}

The setting of initiatives consists of the institutions that influence the process of scaling. The general literature on bottom-up initiatives contributed the most to the concept of institutional factors, but it was also substantially covered in more specific articles on grassroots initiatives (59\% of 22) and in the literature on social entrepreneurship (41\% of 56). The analysis showed that the process of scaling was influenced by the formal and informal rules (mentioned in $49 \%$ of all articles), and by support, which is being done through supplying funds, through knowledge and training, or through network relations (covered in $79 \%$ of all articles).

\section{Rules}

As for rules, governments obviously play a key role in designing and implementing these. However, other actors-e.g. sector organizations-can also influence these rules. Space for experimentation, flexible rules, a favourable business environment and political will are crucial for scaling local initiatives (f.i. Vergragt and Brown 2012; Radywyl and Biggs 2013; Biggs et al. 2010; Jenson 2017; Bailey et al. 2010; Awoonor-Williams et al. 2013; Biehl 2007). Even a lack of rules can be favourable to social entrepreneurs (Gutberlet et al. 2016; Gluckler and Lenz 2016). Studies done in developing countries showed that fragile regimes might decrease the social and environmental impact (Ault 2016). However, stable regimes with strict rules could also frustrate initiatives with their red tape resulting from the bureaucratic system (Kempers et al. 2015).

\section{Support}

Apart from rules, there seemed to be consensus about the facilitating and encouraging role that government could have in supporting local initiatives. Based on case studies, some researchers also came up with ideas how government could fill in this role. For example, by organizing train-the- trainer (Spiegel et al. 2011), by connecting local initiatives with standards on higher levels (Riisgaard 2011) and EU policy (Osterblom et al. 2010) or by co-management (Marin and Berkes 2010) or workshops (Bremer et al. 2016). Although government is often mentioned as a major actor in the institutional environment, there are other players in the field. Ngo's are mentioned, and large companies and philanthropy may also stimulate the development of small initiatives by providing knowledge, money and access to networks (f.i. Quinn et al. 2014; Harvey et al. 2011). Ashoka might be an example of institutional support. This worldwide network stimulates and supports the most innovative entrepreneurial solutions to social and environmental challenges, for instance by training the right skills.

So, what do we know about how institutional factors influence actor characteristics, strategic choices and impact? A favourable business environment will stimulate the start-up activities of grassroots initiatives and social enterprises and the space to experiment will help to scale. For social constructionists and engineers, rules might even be target for system change (Radywyl and Biggs 2013). In this way, rules influence the ambition of the actor. Institutional factors also influence the focus on either the economic or the social logic. For example, some studies done in developing countries show that fragile regimes increase pressure on social entrepreneurs to shift their focus to wealthier clients as they lack the support from government which would allow them to maintain a focus on poorer clients. If they do not shift, they go out of business (Ault 2016). As logic is positively related to impact, regime indirectly influences the level of impact too.

Supporting by funds, network and knowledge influence both the actor's ability to scale and the structure choices that are made. Institutional factors can also influence impact directly by way of adjusting rules, stimulating public debate, or by changing of behaviour inspired by the success of a social entrepreneur. However, a precondition would be the actor's willing to change (Mahama 2012; Awoonor-Williams et al. 2013; Biehl 2007).

In sum, the institutional factors can be categorized in rules and support. The institutional environment is important since it influences actor characteristics, strategic choices as well as impact. The institutional setting influences both the actor's willingness and ability to scale. The institutional environment also affects the strategic choices for a certain type of structure, but we can only assume a relation to pathway. It could also have influence on how much social and environmental impact is created, but the literature in our corpus does not provide clear evidence for this relation. 


\section{Framework for Scaling Social and Sustainable Initiatives}

The purpose of our review was to combine literature on social entrepreneurship with that of grassroots innovation and bottom-up initiatives to find out why and how social and sustainable initiatives scale. The current academic knowledge about scaling is highly fragmented and anecdotal. In addition, there was much confusion about terms and relevant factors. For that reason, we focused our research on reducing conceptual confusion and building a framework of the different factors and relations in the process of scaling bottom-up initiatives.

The review of 133 academic articles resulted in a framework (Fig. 2) that reflects the current state of the field. It presents a concise overview of key theoretical concepts in the literature. Based on the literature, we first distinguish two choices in the scaling process: pathway (scaling up and scaling out) and structure (organizational form). Successful scaling implies more social or environmental impact. We chose the perspective of the initiative and categorized the influential factors for scaling in 'actor characteristics' (willingness and ability) and 'institutional factors' (rules and support).

The literature review provides important insights into the process of scaling. Our analysis of the literature highlights that:

Fig. 2 Framework for "scaling social and sustainable initiatives'
1. Actor's scale ambition, hybrid logic and entrepreneurial and leadership skills are positively related to the level of impact realized through scaling;

2. Open structures may generate speed and more social and environmental impact (but we also found some critical views on this relation);

3. A collaborative structure dominates in grassroots literature, and this may be caused by focus on the local community and less desire for control;

4. An institutional environment in which there is room to experiment with different approaches and strategies helps the initiative to scale.

This systematic literature review contributes to the literature on the scaling of local initiatives by combining separate bodies of literature-the literature on grassroots innovation, bottom-up initiatives and social entrepreneurship —and analysing the similarities and differences between these literatures. The review resulted in a compact framework that provides an overview of the key institutional factors, actor characteristics, strategic choices and impact. The framework can form a basis for further research.

The framework highlights that scaling social and sustainable initiatives is complex as there are many variables and the complex interactions between all these variables are not yet well understood. We need a better understanding of the interaction of variables and dynamics in the

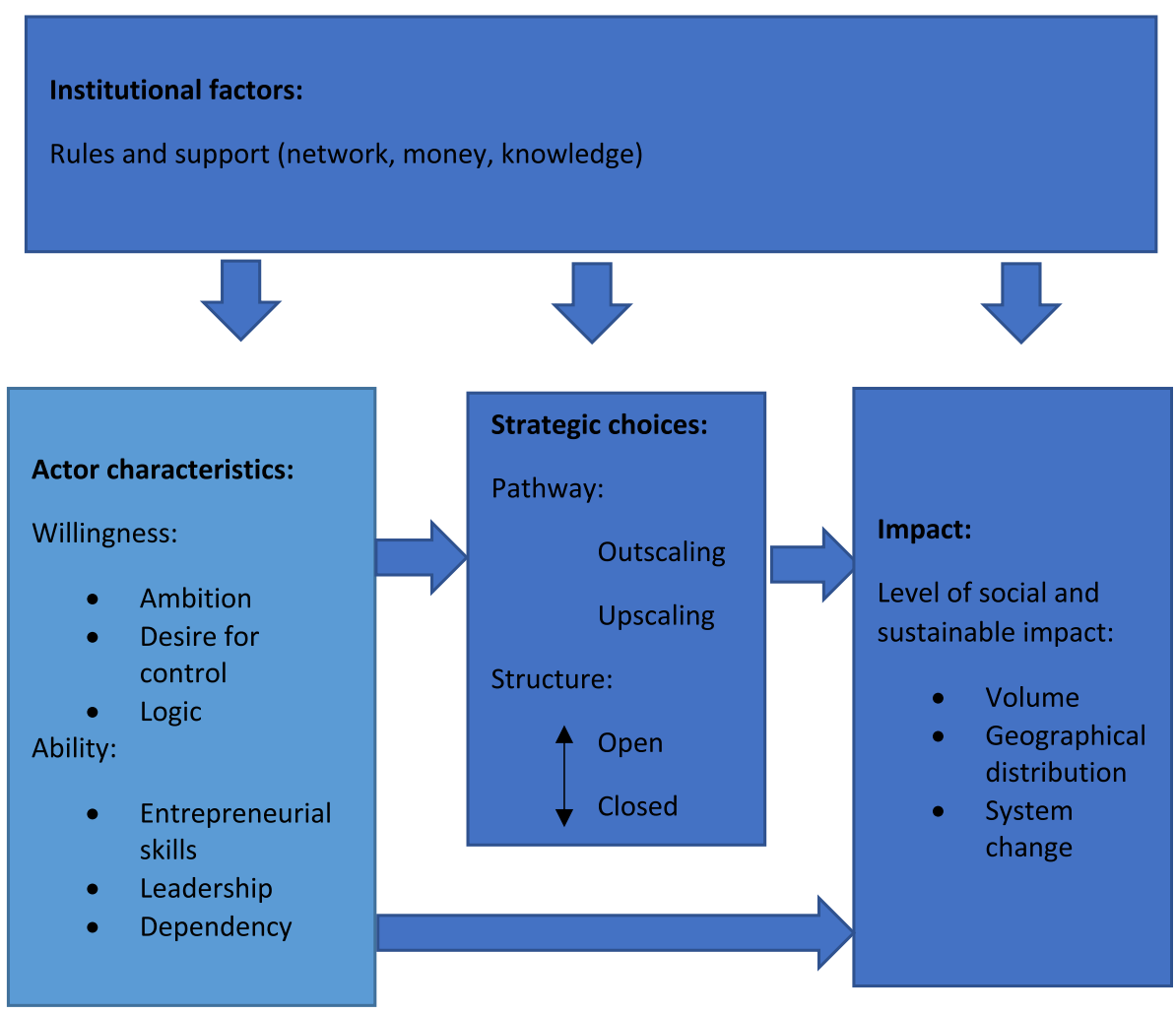


framework and further explore whether the relations between actor characteristics, strategic choices and impact are linear. Time must be taken into consideration as well, as speed seems to be related to structure choice and we do not know to what extent strategic choices could change over time.

We suggest further exploration of the framework in a specific branch or specific topic, like social initiatives in healthcare or sustainable initiatives in the food industry. This will help to explore the different relations and dynamics in the framework more in detail. Also comparing results across different branches and topics could be potentially fruitful as our literature review showed that combining bodies of literature reduces fragmentation of the academic literature and is of benefit to more than one discipline.

To conclude, this papers highlights that actors need a facilitating context, the willingness and the ability to scale and a strategy that works for them to realize either a better (commercial) dissemination or a stronger impact on policies. There is no evidence for a 'miracle cure' as the complex interactions between actors, environments, strategies and impact are dynamic and interactive. Scaling requires 'contextual work', and an in-depth empirical analysis of this type of work is needed to further enhance our understanding of these patterns of scaling.

Funding There was no external funding for this study.

\section{Compliance with Ethical Standards}

Conflict of interest The authors declare that they have no conflict of interest.

Open Access This article is licensed under a Creative Commons Attribution 4.0 International License, which permits use, sharing, adaptation, distribution and reproduction in any medium or format, as long as you give appropriate credit to the original author(s) and the source, provide a link to the Creative Commons licence, and indicate if changes were made. The images or other third party material in this article are included in the article's Creative Commons licence, unless indicated otherwise in a credit line to the material. If material is not included in the article's Creative Commons licence and your intended use is not permitted by statutory regulation or exceeds the permitted use, you will need to obtain permission directly from the copyright holder. To view a copy of this licence, visit http://creativecommons. org/licenses/by/4.0/.

\section{References}

Andre, K., \& Pache, A. C. (2016). From caring entrepreneur to caring enterprise: Addressing the ethical challenges of scaling up social enterprises. Journal of Business Ethics, 133, 659-675.

Andrews, J. O., Tingen, M. S., Jarriel, S. C., Caleb, M., Simmons, A., Brunson, J., et al. (2012). Application of a CBPR framework to inform a multi-level tobacco cessation intervention in public housing neighborhoods. American Journal of Community Psychology, 50, 129-140.

Ault, J. K. (2016). An institutional perspective on the social outcome of entrepreneurship: Commercial microfinance and inclusive markets. Journal of International Business Studies, 47, 951-967.

Auvignet, C., \& Lloret, A. (2015). Understanding social change through catalytic innovation: Empirical findings in Mexican social entrepreneurship. Canadian Journal of Administrative Sciences-Revue Canadienne Des Sciences De L Administration, $32,238-251$.

Awoonor-Williams, J. K., Bawah, A. A., Nyonator, F. K., Asuru, R., Oduro, A., Ofosu, A., et al. (2013). The Ghana essential health interventions program: A plausibility trial of the impact of health systems strengthening on maternal and child survival. Bmc Health Services Research, 13, S3.

Bailey, I., Hopkins, R., \& Wilson, G. (2010). Some things old, some things new: The spatial representations and politics of change of the peak oil relocalisation movement. Geoforum, 41, 595-605.

Bason, C. (2010). Leading public sector innovation: Co-creating for a better society. Bristol: The Policy Press.

Becker, S., Kunze, C., \& Vancea, M. (2017). Community energy and social entrepreneurship: Addressing purpose, organisation and embeddedness of renewable energy projects. Journal of Cleaner Production, 147, 25-36.

Beckmann, M., \& Zeyen, A. (2014). Franchising as a strategy for combining small and large group advantages (logics) in social entrepreneurship: A Hayekian perspective. Nonprofit and Voluntary Sector Quarterly, 43, 502-522.

Biehl, J. (2007). Pharmaceuticalization: AIDS treatment and global health politics. Anthropological Quarterly, 80, 1083-1126.

Biggs, R., Westley, F. R., \& Carpenter, S. R. (2010). Navigating the back loop: Fostering social innovation and transformation in ecosystem management. Ecology and Society, 15, 9.

Bocken, N. M. P. (2015). Sustainable venture capital-Catalyst for sustainable start-up success? Journal of Cleaner Production, 108, 647-658.

Bocken, N. M. P., Fil, A., \& Prabhu, J. (2016). Scaling up social businesses in developing markets. Journal of Cleaner Production, 139, 295-308.

Bremer, S., Haque, M. M., Haugen, A. S., \& Kaiser, M. (2016). Inclusive governance of aquaculture value-chains: Co-producing sustainability standards for Bangladeshi shrimp and prawns. Ocean \& Coastal Management, 131, 13-24.

Calvo-Ugarteburu, G., Raemaekers, S., \& Halling, C. (2017). Rehabilitating mussel beds in Coffee Bay, South Africa: Towards fostering cooperative small-scale fisheries governance and enabling community upliftment. Ambio, 46, 214-226.

Cloutier, G., Joerin, F., Dubois, C., Labarthe, M., Legay, C., \& Viens, D. (2015). Planning adaptation based on local actors' knowledge and participation: A climate governance experiment. Climate Policy, 15, 458-474.

Cook, D. J., Mulrow, C. D., \& Haynes, R. B. (1997). Systematic reviews: Synthesis of best evidence for clinical decisions. Annals of Internal Medicine, 126(5), 376-380.

De Bruin, A. (2016). Towards a framework for understanding transitional green entrepreneurship. Small Enterprise Research, $23,10-21$.

Doberstein, C. (2016). Designing collaborative governance decisionmaking in search of a 'collaborative advantage'. Public Management Review, 18, 819-841.

Elbakidze, M., Angelstam, P. K., Sandstrom, C., \& Axelsson, R. (2010). Multi-stakeholder collaboration in Russian and Swedish model forest initiatives: Adaptive governance. Ecology and Society, 15, 14. 
Eshima, Y., \& Anderson, B. S. (2017). Firm growth, adaptive capability, and entrepreneurial orientation. Strategic Management Journal, 38, 770-779.

Fosfuri, A., Giarratana, M. S., \& Roca, E. (2016). Social business hybrids: Demand externalities, competitive advantage, and growth through diversification. Organization Science, 27, $1275-1289$.

Fung, A. (2015). Putting the public back into governance: The challenges of citizen participation and its future. Public Administration Review, 75, 513-522.

Gasperi, D., Pennisi, G., Rizzati, N., Magrefi, F., Bazzocchi, G., Mezzacapo, U., et al. (2016). Towards regenerated and productive vacant areas through urban horticulture: Lessons from Bologna, Italy. Sustainability, 8, 1347.

Geuijen, K. (2014). Maatschappelijke meerwaarde creëren in publieke netwerken: waartoe en hoe? Bestuurswetenschappen, 68(1), 86-96.

Gutberlet, J., Kain, J. H., Nyakinya, B., Ochieng, D. H., Odhiambo, N., Oloko, M., et al. (2016). Socio-environmental entrepreneurship and the provision of critical services in informal settlements. Environment and Urbanization, 28, 205-222.

Harvey, C., Maclean, M., Gordon, J., \& Shaw, E. (2011). Andrew Carnegie and the foundations of contemporary entrepreneurial philanthropy. Business History, 53, 425-450.

Hatzl, S., Seebauer, S., Fleiss, E., \& Posch, A. (2016). Market-based vs. grassroots citizen participation initiatives in photovoltaics: A qualitative comparison of niche development. Futures, 78-79, 57-70.

Hermans, F., Roep, D., \& Klerkx, L. (2016). Scale dynamics of grassroots innovations through parallel pathways of transformative change. Ecological Economics, 130, 285-295.

Hossain, M. (2016). Grassroots innovation: A systematic review of two decades of research. Journal of Cleaner Production, 137, 973-981.

Hufen, J. A. M., \& Koppenjan, J. F. M. (2015). Local renewable energy cooperatives: Revolution in disguise? Energy Sustainability and Society, 5, 1-14.

Jenson, J. (2017). Modernising the European social paradigm: Social investments and social entrepreneurs. Journal of Social Policy, 46, 31-47.

Kempers, J., Ketting, E., Chandra-Mouli, V., \& Raudsepp, T. (2015). The success factors of scaling-up Estonian sexual and reproductive health youth clinic network-From a grassroots initiative to a national programme 1991-2013. Reproductive Health, 12, 2.

Kirwan, J., Ilbery, B., Maye, D., \& Carey, J. (2013). Grassroots social innovations and food localisation: An investigation of the Local Food programme in England. Global Environmental ChangeHuman and Policy Dimensions, 23, 830-837.

Kitchenham, B. (2004). Procedures for performing systematic reviews (Technical Report No. TR/SE-0401 and 0400011T.1). NICTA, Keele University, Lyme, Newcastle-under-Lyme (Staffordshire)

Kraus, S., \& Rigtering, C. (2017). Strategic corporate entrepreneurship: A configuration approach-based case study. International Journal of Entrepreneurial Venturing, 9(2), 101-121.

Krzeminska, A., \& Zeyen, A. (2017). A stewardship cost perspective on the governance of delegation relationships: The case of social franchising. Nonprofit and Voluntary Sector Quarterly, 46, 71-91.

Loosemore, M. (2015). Building a new third construction sector through social enterprise. Construction Management and Economics, 33, 724-739.

Mahama, A. (2012). 2012 international year for sustainable energy for all: African Frontrunnership in rural electrification. Energy Policy, 48, 76-82.
Mair, J., Wolf, M., \& Seelos, C. (2016). Scaffolding: A process of transforming patterns of inequality in small-scale societies. Academy of Management Journal, 59, 2021-2044.

Marin, A., \& Berkes, F. (2010). Network approach for understanding small-scale fisheries governance: The case of the Chilean coastal co-management system. Marine Policy, 34, 851-858.

Martiskainen, M. (2017). The role of community leadership in the development of grassroots innovations. Environmental Innovation and Societal Transitions, 22, 78-89.

Mills, E. J., Montori, V. M., Ross, C. P., Shea, B., Wilson, K., \& Guyatt, G. H. (2005). Systematically reviewing qualitative studies complements survey design: An exploratory study of barriers to paediatric immunisations. Journal of Clinical Epidemiology, 58(11), 1101-1108.

Morris, M. H., Webb, J. W., \& Franklin, R. J. (2011). Understanding the manifestation of entrepreneurial orientation in the nonprofit context. Entrepreneurship Theory and Practice, 35, 947-971.

Nel, E., Hill, T., \& Binns, T. (1997). Development from below in the 'New' South Africa: The case of Hertzog Eastern Cape. Geographical Journal, 163, 57-64.

Osterblom, H., Gardmark, A., Bergstrom, L., Muller-Karulis, B., Folke, C., Lindegren, M., et al. (2010). Making the ecosystem approach operational-Can regime shifts in ecological-and governance systems facilitate the transition? Marine Policy, 34, 1290-1299.

Perrini, F., Vurro, C., \& Costanzo, L. A. (2010). A process-based view of social entrepreneurship: From opportunity identification to scaling-up social change in the case of San Patrignano. Entrepreneurship and Regional Development, 22, 515-534.

Pless, N. M., \& Appel, J. (2012). In pursuit of dignity and social justice: changing lives through $100 \%$ inclusion-How Gram Vikas fosters sustainable rural development. Journal of Business Ethics, 111, 389-411.

Popay, J. (2005). Moving beyond floccinaucinihilipilification: Enhancing the utility of systematic reviews. Journal of Clinical Epidemiology, 58(11), 1079-1080.

Quinn, R., Tompkins-Stange, M., \& Meyerson, D. (2014). Beyond grantmaking: Philanthropic foundations as agents of change and institutional entrepreneurs. Nonprofit and Voluntary Sector Quarterly, 43, 950-968.

Radywyl, N., \& Biggs, C. (2013). Reclaiming the commons for urban transformation. Journal of Cleaner Production, 50, 159-170.

Reeves, A., Lemon, M., \& Cook, D. (2014). Jump-starting transition? Catalysing grassroots action on climate change. Energy Efficiency, 7, 115-132.

Riisgaard, L. (2011). Towards more stringent sustainability standards? Trends in the cut flower industry. Review of African Political Economy, 38, 435-453.

Roy, M. J., Donaldson, C., Baker, R., \& Kerr, S. (2014). The potential of social enterprise to enhance health and well-being: A model and systematic review. Social Science \& Medicine, 123, 182-193.

Trau, F. (2017). The organisational factor and the growth of firms. Cambridge Journal of Economics, 41(3), 749-774. https://doi. org/10.1093/cje/bev082.

Santos, F. M. (2012). A positive theory of social entrepreneurship. Journal of Business Ethics, 111, 335-351.

Scheuerle, T., \& Schmitz, B. (2016). Inhibiting factors of scaling up the impact of social entrepreneurial organizations-A comprehensive framework and empirical results for Germany. Journal of Social Entrepreneurship, 7, 127-161.

Seyfang, G., \& Smith, A. (2007). Grassroots innovations for sustainable development: Towards a new research and policy agenda. Environmental Politics, 16(4), 584-603.

Seyfang, G., \& Longhurst, N. (2013a). Desperately seeking niches: Grassroots innovations and niche development in the community 
currency field. Global Environmental Change-Human and Policy Dimensions, 23, 881-891.

Seyfang, G., \& Longhurst, N. (2013b). Growing green money? Mapping community currencies for sustainable development. Ecological Economics, 86, 65-77.

Smith, A., Fressoli, M., \& Thomas, H. (2014). Grassroots innovation movements: Challenges and contributions. Journal of Cleaner Production, 63, 114-124.

Smith, B. R., Kistruck, G. M., \& Cannatelli, B. (2016). The impact of moral intensity and desire for control on scaling decisions in social entrepreneurship. Journal of Business Ethics, 133, 677-689.

Smith, B. R., \& Stevens, C. E. (2010). Different types of social entrepreneurship: The role of geography and embeddedness on the measurement and scaling of social value. Entrepreneurship and Regional Development, 22, 575-598.

Smith, V. H., \& McBride, R. C. (2015). Key ecological challenges in sustainable algal biofuels production. Journal of Plankton Research, 37, 671-682.

Sofo, R. (2008). Beyond NCLB and AYP: One superintendent's experience of school district reform. Harvard Educational Review, 78, 391-409.

Spiegel, J. M., Breilh, J., Beltran, E., Parra, J., Solis, F., Yassi, A., et al. (2011). Establishing a community of practice of researchers, practitioners, policy-makers and communities to sustainably manage environmental health risks in Ecuador. BMC International Health and Human Rights, 11, S5.

Tranfield, D., Denyer, D., \& Smart, P. (2003). Towards a methodology for developing evidence-informed management knowledge by means of systematic review. British Journal of Management, 14, 207-222.

Vergragt, P. J., \& Brown, H. S. (2012). The challenge of energy retrofitting the residential housing stock: Grassroots innovations and socio-technical system change in Worcester, MA. Technology Analysis \& Strategic Management, 24, 407-420.

Voltan, A., \& De Fuentes, C. (2016). Managing multiple logics in partnerships for scaling social innovation. European Journal of Innovation Management, 19, 446-467.

Warnecke, T., \& Houndonougbo, A. N. (2016). Let there be light: Social enterprise, solar power, and sustainable development. Journal of Economic Issues, 50, 362-372.

Westley, F., Antadze, N., Riddell, D. J., Robinson, K., \& Geobey, S. (2014). Five configurations for scaling up social innovation: Case examples of nonprofit organizations from Canada. Journal of Applied Behavioral Science, 50, 234-260.

Zahra, S. A., Rawhouser, H. N., Bhawe, N., Neubaum, D. O., \& Hayton, J. C. (2008). Globalization of social entrepreneurship opportunities. Strategic Entrepreneurship Journal, 2, 117-131.

Zahra, S. A., Gedajlovic, E., Neubaum, D. O., \& Shulman, J. M. (2009). A typology of social entrepreneurs: Motives, search processes and ethical challenges. Journal of Business Venturing, $24,519-532$.

Publisher's Note Springer Nature remains neutral with regard to jurisdictional claims in published maps and institutional affiliations. 